\title{
Company Tax Reform in Europe and its Effect on Collusive Behavior*
}

\author{
Dirk Schindler ${ }^{\dagger}$ \\ University of Konstanz \\ Guttorm Schjelderup \\ Norwegian School of Economics and Business Administration and CESifo
}

30 March, 2006

\begin{abstract}
We study how harmonization of corporate tax systems affects the stability of international cartels. We show that tax base harmonization reinforces collusive agreements, while harmonization of corporate tax rates may destabilize or stabilize cartels. We also find that bilateral and full harmonization to a common standard is worse from society's point of view than unilateral harmonization to a minimum tax standard.
\end{abstract}

JEL Classification: H87, L1

Keywords; Corporate tax systems, tacit collusion

*Dirk Schindler gratefully acknowledged financial support from the Volkswagen-Stiftung, and both authors acknowledged financial support from the Research Council of Norway.

${ }^{\dagger}$ Dirk Schindler, University of Konstanz, Fach D 133, 78457 Konstanz, Germany; email: Dirk.Schindler@uni-konstanz.de; phone +49-7531-883691, fax +49-7531-884101.

${ }_{\ddagger}^{\ddagger}$ Guttorm Schjelderup, Department of Economics, Norwegian School of Economics and Business Administration, Helleveien 30, 5045 Bergen, Norway; email: Guttorm.Schjelderup@nhh.no; phone: $+47-55959238$, fax $+47-5595953$. 


\section{Introduction}

The last forty years have seen a number of proposals to approximate corporate tax bases and tax rates in Europe in order to level the playing field for business competition. The recent report by the European Commission on the future of company taxation in Europe (Commission of the European Communities, 2001), points out that differences in national corporate tax systems affect location decisions of firms, impose barriers to cross-border investments, impair the efficiency in the capital market, and foster international tax planning. ${ }^{1}$ To remedy these problems the Commission argues that there is a need for coordination of corporate tax systems among EU member states. The Commission's report shows that there is large variation in effective corporate tax rates across EU member states due to tax rate and tax base differentials. The Commission's main proposal is to move towards a consolidated tax base for European multinational companies, to be allocated across member states through a formula apportionment system. This proposal entails a certain degree of tax base harmonization. The alternative road ahead pointed out by the Commission, is one of harmonization of national tax bases and tax rates within the current system of corporate taxation systems among the EU member states. ${ }^{2}$

The need for a level playing field in the European Union has also been highlighted recently by the entry of new EU member states whose effective tax rates often are significantly below those of 'old' member states. Illustrative of the problem is Nicolas Sarkozy (French Secretary of the Interior and at the time minister of finance and economic affairs) who proposed to refuse payment of most EU-subsidies (i.e., from Structural Funds) to the new EU-countries, whose effective tax rates are significantly below EU-average, in order to prevent their tax advantage from creating "excessive" tax competition. ${ }^{3}$

This paper argues that the discussion over tax rates and base approximation has overlooked the effects harmonization of tax bases or tax rates may have on the stability of international cartels. We show that harmonization of tax rates may increase or decrease collusive behavior, but that the most likely outcome is that it

\footnotetext{
${ }^{1}$ For a survey of proposals and the recent, so-called Bolkestein-report of the EU see Devereux (2004), Mintz (2004) and Sørensen (2004).

${ }^{2}$ Mintz (2004) argues that the focus should be on tax bases rather than tax rates.

${ }^{3}$ See, e.g., Financial Times Deutschland, September 7, 2004, and Neue Züricher Zeitung, September 8, 2004. Countries like, i.e., Lithuania or Hungary have lowered their (effective) tax rates to $13 \%$ resp. $16 \%$ in order to attract multinationals from established member states.
} 
reinforces incentives to stay in cartels. Furthermore, any type of harmonization of tax bases is always undesirable from society's point of view, but bilateral and full harmonization to a common standard is worse than unilateral harmonization to a minimum tax standard. ${ }^{4}$ The implication of our analysis is that, on the one hand, there are very clear negative effects of harmonization on collusive behavior, but on the other hand, there are benefits of a level playing field for corporate taxation systems. A full analysis of corporate tax reform needs to address these effects in a unified framework. This is a topic that is left for future research.

Collusive behavior in an international setting has been confirmed by a number of studies and many of these are summarized in Haufler and Schjelderup (2004). In short, international collusive behavior has been established in industries such as pharmaceutical, chemical, cars, diamonds, telecommunications, uranium yellowcake, Canadian potash, cement, plastic pipe, electronics, and wood pulp. ${ }^{5}$ Cooperation within these industries involves price fixing schemes that in some cases have been going on for a decade or more. The costs of such activities, as documented in the empirical literature, are substantial. ${ }^{6}$ The potential damage to the economy by cartels has been highlighted in Monti (2001); "Estimations by the OECD in its recent Report on Hard Core Cartels ${ }^{7}$ have provided dramatic figures. The average increase from price fixing is estimated to amount to $10 \%$ of the selling price and the corresponding reduction of output to be as high as 20\%. In some recent big cases prices have been increased by the cartel participants 30\% to 50\%." 8

The fighting of cartels has been a clear priority of the European Commission. It is therefore a paradox that no link has been made to the possible effects of tax harmonization on collusive behavior in the Commission's reports on corporation tax systems.

The issue of tax harmonization has been discussed extensively in the public finance literature in relation to fiscal externalities between countries. The canonical tax competition model predicts that competition among countries over mobile cap-

\footnotetext{
${ }^{4}$ The latter approach has been adopted by the EU in its efforts to harmonize commodity taxes. See Haufler and Schjelderup (2004) for an analysis.

${ }^{5}$ See Haufler and Schjelderup (2004) for a survey.

${ }^{6}$ See e.g., Slade (1995), Scherer (1996), King (1997) and Steen and Sørgard (1999).

${ }^{7}$ OECD 2000.

${ }^{8}$ The industries involved are graphite electrodes and citric acid.
} 
ital leads to too low tax rates and underprovision of public goods in equilibrium. ${ }^{9}$ From this model follows the policy recommendation that tax coordination or harmonization is desirable in order to correct the fiscal externality from competition. However, this view is challenged by the Public Choice literature. Here the argument is that competition in general, and competition among governments in particular, is beneficial because it reduces government waste and disciplines politicians. ${ }^{10}$ These studies, however, do not have competition and collusive behavior as their focal point.

Related to our study is Gendron (2001) who in a closed economy setting analyzes the effect on collusion of alternative loss offset provisions under the corporation tax. He finds that an increase in refunds of tax losses may enhance collusive behavior. More recently, Haufler and Schjelderup (2004) analyze the choice of international tax principle in commodity taxation and how it affects cartel stability. Their results are in line with the results presented in this paper. They find that tax harmonization strengthens collusive behavior irrespective of commodity tax principle in place. To our knowledge there are no other studies that are directly comparable to ours or to the Haufler and Schjelderup study.

Our results are brought forward by using a standard model of dynamic price competition and tacit collusion. ${ }^{11}$ The framework is a two-country, two-firm setting, where the national product markets are of equal size and costs of production are the same for both firms in order to highlight how differences in national tax systems affect the stability of cartels. Section 2 outlines the model and section 3 analyzes cartel stability. Section 4 investigates the effects of bilateral and unilateral tax harmonization, while section 5 offers some concluding remarks.

\section{The model}

We consider two firms, labelled by $i \in\{1,2\}$, which are located in country 1 and 2 , respectively. They produce amounts $x_{i}$ of an identical and homogenous good, and

\footnotetext{
${ }^{9}$ See the seminal papers by Zodrow and Mieszkowski (1986) and Wilson (1986). A survey of the literature is given in Wilson (1999).

${ }^{10}$ E.g., Brennan and Buchanan (1980), McLure (1986), and more recently Rauscher (1998).

${ }^{11}$ The same model has previously been used to study 'reciprocal dumping' in a trade context (see Pinto, 1986), to compare tariffs and quotas (Rotemberg and Saloner, 1989), to study the effects of trade liberalization as in Lommerud and Sørgard (2001), and to compare different exchange rate regimes (Meckl, 1996). Recently, Haufler and Schjelderup (2004) have studied how international principles of value-added taxation affect the stability of collusive agreements.
} 
tacit collusion between the two firms implies that both firms refrain from exporting. Each firm is thus a monopolist in its home market. In each period, either firm may defect from this implicit agreement and export to the other market, but such action causes future retaliation by the other firm. If firm $i$ defects, it does so in the first period $(t=0)$ and exports to country $j$. It will catch firm $j$ by surprise and we define this as the deviation phase of the game. In the following period(s), however, firm $j$ retaliates by exporting to market $i$. This is the punishment phase of the game. Furthermore, as in the literature on repeated games we assume a trigger strategy which implies that firm $j$ will retaliate by exporting to market $i$ in all subsequent periods. Hence, if one firm defects in period $t=0$, duopoly competition prevails in both markets in $t=1,2, \ldots \infty$. Furthermore, we assume that national markets are segmented, i.e., different producer prices can be set in the two national markets under both monopolistic and duopolistic market structures.

In the following, we denote by $\pi_{i}^{M}$ the profit of firm $i$ if it acts as a monopolist in its domestic market, $\pi_{i}^{E}$ is the extra profit in period 0 when firm $i$ defects and exports into the other market, and $\pi_{i}^{D}$ is the total duopoly profit (earned in both markets together) of firm $i$ under mutual export competition. Denoting $\delta_{i}$ as the discount factor of firm $i\left(0<\delta_{i}<1\right)$, defection from the cartel solution is unprofitable whenever the present value of staying forever in the cartel, $\pi_{i}^{M} /\left(1-\delta_{i}\right)$, is greater than or equal to the profits of defecting from the agreement, that is, $\left(\pi_{i}^{M}+\pi_{i}^{E}\right)+\pi_{i}^{D} \delta_{i} /\left(1-\delta_{i}\right)$. Thus, we can write the "stability condition" for the collusive agreement as: ${ }^{12}$

$$
\theta_{i} \geq \bar{\theta}_{i}=\frac{\pi_{i}^{E}}{\pi_{i}^{M}-\pi_{i}^{D}}, \quad \forall i \in\{1,2\},
$$

where $\theta_{i} \equiv \delta_{i} /\left(1-\delta_{i}\right)$ is the relative discount factor of firm $i$, and $\bar{\theta}_{i}$ is the size of this rate that just leaves the firm indifferent between staying in the secret cartel and defecting. The critical values $\bar{\theta}_{i}$ differ between the two firms (as will become clear later) due to differences in the corporate tax system. In general, it is the firm with the higher critical value of $\bar{\theta}_{i}$, which is more likely to break the collusive arrangement. Hence it is this firm's $\bar{\theta}_{i}$ that is binding for the stability of the secret cartel. ${ }^{13}$ For the

\footnotetext{
${ }^{12}$ We assume that $\pi_{i}^{M}>\pi_{i}^{D}$ holds throughout the analysis.

${ }^{13}$ As pointed out by Haufler and Schjelderup (2004): If firm $j$ has the higher critical value of $\bar{\theta}$, then firm $i(i \neq j)$ could improve the stability of the collusive agreement by offering firm $j$ a new contract (for example a fifty-fifty split of the two markets). Such market sharing, however, poses a problem. The reason is that it is much easier to detect a breach of agreement if a firm exports (when it should not) than if it produces beyond the agreed export quota. The cost of monitoring,
} 
analysis to come, it is useful to note that the higher $\bar{\theta}_{i}$ is under a given scenario, the lower is the likelihood that the collusive agreement is stable, since a smaller range of (common) relative discount factors $\theta$ sustains the cartel solution.

\section{$3 \quad$ Profits and cartel stability}

We assume that the size of the market in each country is the same and that firms have the same costs. Demand functions in both markets are linear and given by $x_{i}=a-p_{i}$, where $p_{i}$ is the consumer price, $x_{i}$ is demand, and $a>0$ is a market size parameter that denotes maximum sales at a price of zero which is identical for both countries. In principle we could allow market size differences, but the purpose here is to investigate the effects of differences in corporate tax systems only, and we therefore refrain from analyzing the interaction of taxes with other parameters. ${ }^{14}$

The economic profit of the firm is

$$
\pi_{i}=p_{i} x_{i}-c x_{i}, \quad i=1,2 .
$$

where $c$ is (constant) marginal cost.

We assume that taxable profit differs from economic profit to capture the idea that tax deductible costs in practice deviate from true costs. The deviation may be given various interpretations. First, it is a fact in many countries that certain categories of costs are not tax deductible. Notable examples are alcoholic drinks and bribes. Second, and more importantly, the dividing line between what is deemed an expense - that can be deducted immediately - and what is deemed an investment, which is written off over time, is based on judgement that may not reflect the true economic cost. Third, one may also consider incomplete cost deductions as a proxy for the distortion imposed on firms by the inability of governments to set tax deductible depreciation rates equal to true depreciation rates. ${ }^{15}$

therefore, provides cartels with an incentive to set up exclusive territories (see Marvel, 1982, and Tirole, 1988, pp. 183 and 185).

${ }^{14}$ The effect of differences in market size on cartel stability is examined in Haufler and Schjelderup (2004) in a context of commodity taxes.

${ }^{15}$ The latter problem is well known in public finance and has various effects on firm behavior. See Sinn (1987). 
Taxable profit is given by

$$
\pi_{i}^{\tau}=p_{i} x_{i}-\gamma_{i} c x_{i}, \quad i=1,2
$$

where $\gamma_{i}$ is the share of marginal costs that is tax deductible. In principle $\gamma_{i} \gtreqless 1$, so if $\gamma_{i}<1$, deductions are incomplete in the sense that deductions fall short of true costs, whilst if $\gamma_{i}>1$ deductions are too generous. Only when $\gamma_{i}=1$ are tax deductible costs equal to true costs and the corporate tax system is neutral (i.e., does not affect firm behavior).

Denoting $t_{i}$ as the corporate tax rate after tax profit is

$$
\begin{aligned}
\Pi_{i} & =\pi_{i}-t_{i} \pi_{i}^{\tau}=\left(a-p_{i}\right)\left[p_{i}\left(1-t_{i}\right)-c\left(1-\gamma_{i} t_{i}\right)\right] \\
& =\left(1-t_{i}\right)\left(a-p_{i}\right)\left[p_{i}-c \cdot \frac{1-\gamma_{i} t_{i}}{1-t_{i}}\right] .
\end{aligned}
$$

Maximizing $\Pi_{i}$ with respect to price (or quantity) yields optimal price, quantity, and profit as

$$
p_{i}=\frac{\left(a+\tilde{c}_{i}\right)}{2}, \quad x_{i}=\frac{\left(a-\tilde{c}_{i}\right)}{2}, \quad \text { and } \quad \pi_{i}^{M}=\frac{1-t_{i}}{4} \alpha_{i}^{2}
$$

where $\tilde{c}_{i}\left(\gamma_{i}, t_{i}\right) \equiv \frac{1-\gamma_{i} t_{i}}{1-t_{i}} c \equiv \epsilon_{i} c$ is the effective after tax marginal cost and $\alpha_{i} \equiv$ $\left(a-\tilde{c}_{i}\right)>0$ for positive sales to occur. $\epsilon_{i}$ is a tax wedge. If the tax code allows full deductibility of costs $\left(\gamma_{i}=1\right)$ we have that $\epsilon_{i}=1$, and $\tilde{c}_{i}=c$. The corporate tax rate is then lump sum in nature, since it does not affect the behavior of the firm. In general we assume that this neutrality property does not hold.

From (2) it then follows that the tax code in fact implements two taxes. First, we have a tax on pure economic profits with tax rate $t_{i}$. Second, there is a tax on costs with tax rate $\tau_{i}=\epsilon_{i}-1$. When $\gamma_{i}>1$ this implies a subsidy on costs while the opposite is true if $0<\gamma_{i}<1$.

For ease of exposition we sometimes refer to a situation where a country is a low tax country. By this we mean;

Definition 1 Country $i$ is a low tax country if it has a constellation of tax rate and tax deductibility rule that makes the firm located in country $i$ a low cost firm that is, $\tilde{c}_{j}>\tilde{c}_{i}\left(\Leftrightarrow \epsilon_{j}>\epsilon_{i}, i \neq j\right)$. 
For given symmetrical marginal costs $c$, Definition 1 implies a combination of tax rates and deductibility rules such that either condition (i) or (ii) below is satisfied:

(i) $t_{i} \leq t_{j}$ and $1>\gamma_{i} \geq \gamma_{j}{ }^{16}$ or

(ii) $t_{i} \leq t_{j}$ and $\gamma_{i} \geq \gamma_{j}>1$, whereby the difference in tax rates is small enough or the difference in deductibility rules is large enough in order to sustain $\epsilon_{j}>\epsilon_{i}{ }^{17}$

In what follows we assume that country 1 is the low tax country and thus that firm 1 has the lowest marginal costs (i.e., $\tilde{c}_{1}<\tilde{c}_{2}$ ).

\subsection{Deviation from cartel agreement}

If firm 1 deviates and exports to country 2 in period 1, it sets a price on its exports $\left(p_{2}^{1}\right)$ equal to its monopoly price in country 1 , since this price - given firm $1^{\prime} s$ tax advantage over firm 2 - is below the monopoly price of firm 2. Hence, $p_{2}^{1}=\frac{1}{2}\left(a+\tilde{c}_{1}\right)<p_{2}$. As a consequence, $\pi_{1}^{E}\left(=\pi_{1}^{M}\right)>\pi_{2}^{M}$, and profit from deviating is

$$
\pi_{1}^{E}=\frac{1-t_{1}}{4} \alpha_{1}^{2}
$$

If firm 2 deviates and exports to country 1, it cannot use its profit maximizing (monopoly) price since $p_{2}>p_{1}$. Therefore, the best strategy for firm 2 is to slightly undercut the price of firm 1 by setting its export price $p_{1}^{2}$ just below $\frac{\left(a+\tilde{c}_{1}\right)}{2}\left(=p_{1}\right)$, thereby sweeping the market and earning profit of

$$
\pi_{2}^{E}=\frac{\left(1-t_{2}\right)}{4} \alpha_{1}\left[\alpha_{1}-2\left(\tilde{c}_{2}-\tilde{c}_{1}\right)\right]
$$

In the punishment phase, both firms compete over prices. Since firm 1 is located in the low tax country it has the lower effective marginal costs $\left(\tilde{c}_{1}<\tilde{c}_{2}\right)$. Thus, it will set its price marginally below the effective marginal cost of firm 2, that is, $\tilde{c}_{2}$. Since goods are homogeneous, firm 1 is then the sole provider in both markets, and earns a profit in each country equal to $\left(a-p_{1}\right)\left[p_{1}\left(1-t_{1}\right)-c\left(1-\gamma_{1} t_{1}\right)\right]$. Total

\footnotetext{
${ }^{16}$ Note that $\frac{\partial \tilde{c}_{i}}{\partial \gamma_{i}}=-\frac{t_{i} c}{1-t_{i}}<0$, thus an increase in tax deductible costs decreases the effective cost of the firm for all values of $\gamma_{i}$.

${ }^{17}$ These restrictions are necessary because $\frac{\partial \tilde{c}_{i}}{\partial t_{i}}=\frac{1-\gamma_{i}}{\left(1-t_{i}\right)^{2}} c<0$ if $\gamma_{i}>1$.
} 
profit in both markets corresponds to these expressions multiplied by 2 and can be written as

$$
\pi_{1}^{D}=2\left(1-t_{1}\right) \alpha_{2}\left(\tilde{c}_{2}-\tilde{c}_{1}\right)
$$

In contrast, firm 2 derives profit of

$$
\pi_{2}^{D}=0
$$

in the punishment period.

The critical discount factors for firm 1 and firm 2 can now be written as

$$
\begin{gathered}
\bar{\theta}_{1}=\frac{\alpha_{1}^{2}}{\alpha_{1}^{2}-8 \alpha_{2}\left(\tilde{c}_{2}-\tilde{c}_{1}\right)}, \\
\bar{\theta}_{2}=\frac{\alpha_{1}\left[\alpha_{1}-2\left(\tilde{c}_{2}-\tilde{c}_{1}\right)\right]}{\alpha_{2}^{2}} .
\end{gathered}
$$

\subsection{National differences in corporate tax systems}

In this section we consider equations (6) and (7) in order to determine which firm is more likely to defect from the collusive agreement, depending on assumptions made about national differences in the corporate tax system.

Proposition 1. It is always the firm located in the low tax country (firm 1) that is more likely to break the collusive agreement.

Proof: From Definition 1 we have that since firm 1 is located in a low tax country, then, $\left(\tilde{c}_{2}-\tilde{c}_{1}\right)>0$ and $\alpha_{1}=a-\tilde{c}_{1}>a-\tilde{c}_{2}=\alpha_{2}$. Thus, the numerators $\left(N_{\bar{\theta}_{i}}\right)$ in equations (6) and (7) relate to each other as follows: $N_{\bar{\theta}_{1}}>N_{\bar{\theta}_{2}}$. For the denominators $D_{\bar{\theta}_{1}}$ and $D_{\bar{\theta}_{2}}$, we can use $\alpha_{1}=\alpha_{2}+\left(\tilde{c}_{2}-\tilde{c}_{1}\right)$ and binomial rules in the denominator of (6), to get; $D_{\bar{\theta}_{1}}=\alpha_{1}^{2}-8 \alpha_{2}\left(\tilde{c}_{2}-\tilde{c}_{1}\right)=\left[\alpha_{2}-\left(\tilde{c}_{2}-\tilde{c}_{1}\right)\right]^{2}-4 \alpha_{2}\left(\tilde{c}_{2}-\tilde{c}_{1}\right)$, which shows that $D_{\bar{\theta}_{1}}<D_{\bar{\theta}_{2}}=\alpha_{2}^{2}$, as $\tilde{c}_{2}>\tilde{c}_{1}$. Taken together we have that $N_{\bar{\theta}_{1}}>N_{\bar{\theta}_{2}}$ and $D_{\bar{\theta}_{1}}<D_{\bar{\theta}_{2}}$, which unambiguously implies $\bar{\theta}_{1}>\bar{\theta}_{2}$.

Intuitively, a firm located in a low tax country can gain more than a firm located in a high tax country by defecting from the collusive agreement. The reason is that its cost advantage implies higher profit both in the deviation and in the punishment phase of the game. The low cost firm, therefore, has a smaller range of discount factors (i.e., a higher relative discount factor $\theta$ ) that sustains the cartel solution. 


\section{Tax Harmonization}

We start with the same basic premise as in the previous sections namely that country 1 is a low tax country and firm 1 is a low cost firm. We define a harmonizing company tax reform as one which narrows or eliminates the difference between tax rates and/or deductability rates. We shall refer to unilateral harmonization as the case where one country changes its tax parameters to a minimum standard. Unilateral harmonization has been the vehicle for harmonization of commodity taxes within the European Union. An alternative is to consider a bilateral harmonization process where both countries change their tax rates and/or deductability rules to a common tax and/or deductability rule. ${ }^{18}$

We examine the effects of harmonization by investigating tax base and tax rate harmonization separately. This is done in order to: (i) compare bilateral and unilateral harmonization to see if one is preferable over the other, and (ii) investigate whether it is better to harmonize tax bases or tax rates. Underlying the discussion is an implicit view that monopoly and cartels are undesirable from society's point of view. With equal weights on consumer and producer surplus, it is well known that monopoly produces a deadweight loss that can be reduced by promoting competition.

\subsection{Harmonization of corporate tax rates}

Bilateral harmonization. Starting from $\gamma_{1}>\gamma_{2}$ and $t_{1}<t_{2}$, bilateral harmonization of tax rates to a common level implies $d t_{1}>0$ and $d t_{2}<0$, and we assume that $d t_{1}=\frac{t_{2}-t_{1}}{2}$ and $d t_{2}=-\frac{t_{2}-t_{1}}{2}$. Firm 1 is the most likely firm to defect from the cartel. Let $d \bar{\theta}_{1}^{B}$ denote the change in firm 1's critical discount rate under bilateral harmonization. Then

$$
d \bar{\theta}_{1}^{B}=\left(\frac{\partial \bar{\theta}_{1}}{\partial \tilde{c}_{1}} \frac{\partial \tilde{c}_{1}}{\partial \epsilon_{1}} \frac{\partial \epsilon_{1}}{\partial t_{1}}-\frac{\partial \bar{\theta}_{1}}{\partial \tilde{c}_{2}} \frac{\partial \tilde{c}_{2}}{\partial \epsilon_{2}} \frac{\partial \epsilon_{2}}{\partial t_{2}}\right) \frac{t_{2}-t_{1}}{2} .
$$

Although $\frac{\partial \bar{\theta}_{1}}{\partial \tilde{c}_{1}}<0, \frac{\partial \tilde{c}_{i}}{\partial \epsilon_{i}}>0$, and $\frac{\partial \bar{\theta}_{1}}{\partial \tilde{c}_{2}}>0$ (see the Appendix), the precise effect of the tax rate on the firm's effective cost depends on the size of the tax deduction

\footnotetext{
${ }^{18}$ Both bilateral and unilateral approaches to harmonization have been studied in the tax literature. See Kanbur and Keen (1993), and Keen (1987, 1989).
} 
parameter $\gamma$, since

$$
\frac{\partial \epsilon_{i}}{\partial t_{i}}=\frac{1-\gamma_{i}}{\left(1-t_{i}\right)^{2}} \begin{cases}>0 & \text { if } \gamma_{i}<1 \\ <0 & \text { if } \gamma_{i}>1\end{cases}
$$

Using (8) and (9) we find that

$$
d \bar{\theta}_{1}^{B} \begin{cases}<0 & \text { if } \gamma_{i}<1 \\ >0 & \text { if } \gamma_{i}>1\end{cases}
$$

When the tax code implies incomplete deductions $\left(\gamma_{i}<1\right)$, bilateral harmonization stabilizes the cartel. Increasing the tax rate in country 1 raises effective production costs by firm 1 and narrows the cost differential between the two firms thereby reducing the gain to firm 1 from defecting. Furthermore, lowering the tax rate in country 2 reduces the profit of firm 1 in the punishment phase, since the price firm 1 can charge is a decreasing function of firm 2's effective costs $\left(\tilde{c}_{2}\right)$. In either case, bilateral harmonization when $\gamma_{i}<1$ increases the range of discount rates that supports the cartel solution for firm 1.

In contrast, when the tax deductibility parameter implies a subsidy on costs $\left(\gamma_{i}>1\right)$, bilateral harmonization destabilizes the cartel. An increase in the tax rate in country 1 enhances the cost advantage of firm 1 thereby making it more attractive to deviate. Similarly, a decrease in the tax rate in country 2 lowers the subsidy to firm 2 and increases its effective costs $\left(\tilde{c}_{2}\right)$ allowing firm 1 to earn higher profit in the punishment phase. Consequently, firm 1 is more likely to break out of the cartel.

Unilateral harmonization. Under unilateral harmonization of corporate tax rates, only one country changes its tax rate and the approach taken in the European Union has been to impose a minimum rate that low tax countries must comply with. In line with this we assume that the low tax country (country 1) must adhere to a minimum tax rate $t_{1}^{\min }$. Given that $t_{1}<t_{1}^{\min }<t_{2}$ to begin with, country 1 must increase its tax rate to $t_{1}^{\min }$ whilst country 2 keeps its rate constant. To make our analysis comparable to the bilateral harmonization above, we assume that minimum taxation implies an increase in country 1 by $d t_{1}=\frac{t_{2}-t_{1}}{2}$. Define $d \bar{\theta}_{1}^{U}$ as the change in firm 1's critical discount rate under bilateral harmonization. Then,

$$
d \bar{\theta}_{1}^{U}=\frac{\partial \bar{\theta}_{1}}{\partial \tilde{c}_{1}} \frac{\partial \tilde{c}_{1}}{\partial \epsilon_{1}} \frac{\partial \epsilon_{1}}{\partial t_{1}} \frac{t_{2}-t_{1}}{2}
$$


where the sign of $d \bar{\theta}_{1}^{U}$ depends on the size of $\gamma_{i}$. In particular,

$$
d \bar{\theta}_{1}^{U} \begin{cases}<0 & \text { if } \gamma_{i}<1 \\ >0 & \text { if } \gamma_{i}>1\end{cases}
$$

Qualitatively the result is the same as under bilateral harmonization. Comparing unilateral and bilateral harmonization we know from (10) and (12) that $d \bar{\theta}_{1}^{i}<(>) 0$, $i=B, U$, if $\gamma_{i}<(>) 1$. In particular,

$$
d \bar{\theta}_{1}^{B}-d \bar{\theta}_{1}^{U}=-\frac{t_{2}-t_{1}}{2}\left(\frac{\partial \bar{\theta}_{1}}{\partial \tilde{c}_{2}} \frac{\partial \tilde{c}_{2}}{\partial \epsilon_{2}} \frac{\partial \epsilon_{2}}{\partial t_{2}}\right) \begin{cases}<0 & \text { if } \gamma_{i}<1 \\ >0 & \text { if } \gamma_{i}>1\end{cases}
$$

Bilateral harmonization strengthens the collusive agreement more than unilateral harmonization when $\gamma_{i}<1$, whilst bilateral harmonization weakens the cartel more than unilateral harmonization when $\gamma_{i}>1$. Based on (8), (11), and (13) we may draw the following conclusions;

Proposition 2. Bilateral and unilateral harmonization of corporate tax rates strengthens (weakens) collusive behavior if tax deductible costs are below (above) true economic costs. Bilateral harmonization strengthens the cartel solution more than unilateral harmonization when $\gamma_{i}<1$, whilst bilateral harmonization weakens the cartel solution more than unilateral harmonization when $\gamma_{i}>1$.

\subsection{Harmonization of tax bases}

Bilateral harmonization. We now consider the case of tax base harmonization from the starting point $t_{1}<t_{2}$ and $\gamma_{1}>\gamma_{2}$ with firm 1 as the low-cost firm. Bilateral harmonization to a common rate implies $d \gamma_{1}=-\frac{\gamma_{1}-\gamma_{2}}{2}<0$ and $d \gamma_{2}=\frac{\gamma_{1}-\gamma_{2}}{2}>0$, and the change in the critical discount factor is

$$
d \bar{\theta}_{1}^{B}=\left(-\frac{\partial \bar{\theta}_{1}}{\partial \tilde{c}_{1}} \frac{\partial \tilde{c}_{1}}{\partial \epsilon_{1}} \frac{\partial \epsilon_{1}}{\partial \gamma_{1}}+\frac{\partial \bar{\theta}_{1}}{\partial \tilde{c}_{2}} \frac{\partial \tilde{c}_{2}}{\partial \epsilon_{2}} \frac{\partial \epsilon_{2}}{\partial \gamma_{2}}\right) \frac{\gamma_{1}-\gamma_{2}}{2}
$$

Using (see the Appendix) $\frac{\partial \bar{\theta}_{1}}{\partial \tilde{c}_{1}}<0, \frac{\partial \tilde{c}_{i}}{\partial \epsilon_{i}}>0$ and $\frac{\partial \bar{\theta}_{1}}{\partial \tilde{c}_{2}}>0,(14)$ and

$$
\frac{\partial \epsilon_{i}}{\partial \gamma_{i}}=-\frac{t_{i}}{1-t_{i}}<0 \text { for all } t_{i} \in(0,1)
$$


we have that

$$
d \bar{\theta}_{1}^{B}<0
$$

Harmonizing tax bases bilaterally makes collusive agreements more stable. Narrowing the differential in tax bases shrinks the cost advantage of the low cost firm and reduces profit in the deviation and punishment phase.

Unilateral harmonization. Under unilateral harmonization there is a binding ceiling for depreciations implemented with $\gamma_{2}<\gamma^{\max }<\gamma_{1}$. If we again assume that the ceiling, $\gamma^{\max }$, is the mean of the tax parameters, $\gamma_{1}$ and $\gamma_{2}$, this requires a change in the low-tax country tax base according to $d \gamma_{1}=-\frac{\gamma_{1}-\gamma_{2}}{2}$. This changes the critical discount factor of firm 1 as follows

$$
d \bar{\theta}_{1}^{U}=-\frac{\partial \bar{\theta}_{1}}{\partial \tilde{c}_{1}} \frac{\partial \tilde{c}_{1}}{\partial \epsilon_{1}} \frac{\partial \epsilon_{1}}{\partial \gamma_{1}} \frac{\gamma_{1}-\gamma_{2}}{2}<0,
$$

where from the comparative static results presented above it is clear that harmonization of the tax base even to a minimum level stabilizes the cartel, since it reduces firm 1's incentives to deviate. Comparing bilateral and and unilateral harmonization by taking the difference of (16) and (17) we obtain,

$$
d \bar{\theta}_{1}^{B}-d \bar{\theta}_{1}^{U}=\left(\frac{\gamma_{1}-\gamma_{2}}{2}\right) \frac{\partial \bar{\theta}_{1}}{\partial \tilde{c}_{2}} \frac{\partial \tilde{c}_{2}}{\partial \epsilon_{2}} \frac{\partial \epsilon_{2}}{\partial \gamma_{2}}<0 .
$$

It is clear from (18) that bilateral harmonization has a greater impact on the critical discount factor, thus

Proposition 3. Both bilateral and unilateral harmonization of tax bases strengthens incentives for collusion, but the effect is larger under bilateral harmonization.

Comparing Propositions 2 and 3 it is seen that cartel stability is differently affected by tax rate and tax base harmonization. In the latter case harmonization (unilateral or bilateral) reinforces incentives to stay in the cartel. In contrast, the stability of a cartel under tax rate harmonization depends on the size of the tax deductibility rate. Too generous deduction rules $(\gamma>1)$ destabilize collusive agreements due to the fact that deduction rules in combination with the tax rate are a subsidy (if $\gamma>1$ ) that lowers costs of the low tax firm and enhances its profit in the deviation and punishment phase.

If we relax the assumption of marginal costs being identical in both countries all our results hold and are even enforced if the low cost firm resides in the low tax 
country, that is, if $\epsilon_{i}<\epsilon_{j}$ and $c_{i}<c_{j}$. Crucial for our results then is that Definition 1 is fulfilled. If the opposite constellation is present, that is, $\epsilon_{i}<\epsilon_{j}$ but $c_{i}>c_{j}$, the high cost firm is harmed by harmonization, since the cost differential is widened when the low tax country increases its effective tax burden. Harmonization then delivers a double dividend in the sense that it enhances competition and weakens the incentive for cartel formation. However, strong anecdotical evidence indicates that the latter case is less realistic. Wages and taxes in the Eastern European countries, for example, are substantially lower than in Western Europe indicating that low tax countries host low cost firms.

\subsection{Extension to several countries}

Our analysis can be extended to the case of several countries (i.e., $n>2$ ). Using the same set-up as above where differences in the tax system are the only source of variety, we focus on two cases. In case (i) country 1 is a low-tax country and there are $(n-1)$ identical high tax countries. In case (ii) there are two countries, 1 and 2 , hosting firms with an identical low-cost structure, and $(n-2)$ countries hosting high-cost firms.

In both cases above, a low-cost firm $i$ earns profit $\Pi_{i}^{E}=(n-1) \pi_{i}^{E}$ if it deviates from the cartel and exports to the other $(n-1)$ countries in period 1. As in Section 3.1 it catches its competitors by surprise and sets its monopoly price $p_{i}<p_{j} \forall j$, $j \neq i$ in the deviation phase. Profit in the deviation phase is now $(n-1)$ times higher than previously and ceteris paribus, this weakens cartel stability. However, there may be an offsetting effect (depending on assumptions) since there are more firms that can export to the home market of the firm that breaches the collusive agreement. As a consequence, profit in the punishment phase may fall, and ceteris paribus, this effect enforces incentives to stay in the cartel. Which of these two effects dominates depends on the relative magnitudes of these effects and differs in cases (i) and (ii).

To be specific, in case (i), there are $(n-1)$ identical high tax countries and profit in each of these countries in the punishment period is (as before) zero, whilst the low-cost firm earns a positive profit. Profit in the deviation phase by the low cost firm (firm 1) is $\Pi_{1}^{D}=(n-1) \pi_{1}^{D}$, and is increasing in the number of countries. Thus, 
the critical discount factor of the low-cost firm can be written as

$$
\bar{\Theta}_{i}=\frac{\Pi_{1}^{E}}{\pi_{1}^{M}-\Pi_{1}^{D}}=\frac{(n-1) \cdot \pi_{1}^{E}}{\pi_{1}^{M}-(n-1) \cdot \pi_{1}^{D}}=\frac{\pi_{1}^{E}}{\frac{\pi_{1}^{M}}{n-1}-\pi_{1}^{D}}>\frac{\pi_{1}^{E}}{\pi_{1}-\pi_{1}^{D}}=\bar{\theta}_{1} .
$$

The likelihood of firm $i$ leaving the cartel increases in the number of high-tax countries, as the critical discount factor of the low-cost firm increases disproportionate to the number of countries. Moreover, it can be shown that

$$
\frac{\partial \bar{\Theta}_{i}}{\partial \tilde{c}_{i}}=-\frac{2 \alpha_{i}\left[\frac{\alpha_{i}^{2}}{n-1}-8 \alpha_{j}\left(\tilde{c}_{j}-\tilde{c}_{i}\right)\right]+\frac{\alpha_{i}^{2}}{n-1}\left[6 \alpha_{i}-8\left(\tilde{c}_{j}-\tilde{c}_{i}\right)+(n-2) 8 \alpha_{2}\right]}{\left[\frac{\alpha_{i}^{2}}{n-1}-8 \alpha_{j}\left(\tilde{c}_{j}-\tilde{c}_{i}\right)\right]^{2}}<0
$$

and

$$
\frac{\partial \bar{\Theta}_{i}}{\partial \tilde{c}_{j}}=\frac{8 \alpha_{i}^{2}\left[\alpha_{i}-2\left(\tilde{c}_{j}-\tilde{c}_{i}\right)\right]}{\left[\frac{\alpha_{i}^{2}}{n-1}-8 \alpha_{j}\left(\tilde{c}_{j}-\tilde{c}_{i}\right)\right]^{2}}>0
$$

Thus, qualitatively the effects of harmonizing either tax rates or tax bases are unchanged, if we extend the analysis to several high-tax countries.

In case (ii), where there are two identical low-cost firms, the relevant critical discount factor changes significantly. In the punishment phase, firm 1, which is assumed to break the collusive agreement, has to cope with the other low-cost firm and, hence, the price is driven down to equal the effective marginal cost in all markets under attack. Thus, profit in the punishment phase will be equal to zero and we get

$$
\bar{\Theta}_{i}=\frac{\Pi_{i}^{E}}{\pi_{i}^{M}}=(n-1) \frac{\pi_{i}^{E}}{\pi_{i}^{M}}=n-1 \quad i=\{1,2\},
$$

because $\pi_{i}^{E}=\pi_{i}^{M}$ from (3) and (4). Compared with the original two-country model, the increased profit in the deviation phase increases the critical discount factor, whereas the vanishing profits in the punishment phase have a depressing effect. This trade-off remains ambiguous and we cannot compare the discount factor in equation (22) with the one in (6).

However, we get

$$
\frac{\partial \bar{\Theta}_{i}}{\partial \tilde{c}_{i}}=0=\frac{\partial \bar{\Theta}_{i}}{\partial \tilde{c}_{j}} \quad \forall i=\{1,2\}, j=\{3, \ldots, n\}
$$

Thus, for a low cost firm, tax harmonization (whether base or rate) does not affect 
the decision to leave the cartel. The intuition is that there is always another identical firm and the critical discount factor is only driven by the number of countries, because there are additional profits (which are proportionally increasing in the number of countries) only in the deviation phase. Hence, we conclude

Proposition 4. If the number of countries increases $(n>2)$ and

(i) if there is only one low-tax country, all results from the two-country setting are preserved qualitatively.

(ii) if there are at least two identical low-tax countries within the Union, neither coordination in tax rates nor in tax bases has any influence on cartel stability.

\section{Concluding remarks}

This paper has shown that harmonization of tax rates and tax bases affects the stability of international cartels and that for the reasonable assumption of incomplete tax deductible expenses, both bilateral and unilateral harmonization stabilizes collusive agreements. Unilateral harmonization to a minimum standard is preferable to bilateral harmonization in the sense that it has a smaller effect on the incentive to stay in the cartel. Our results strengthen previous arguments against harmonization brought forward in the public choice literature (e.g., Brennan and Buchanan) pertaining to collusive behavior by governments, and are also in line with more recent studies, which show that tax harmonization is generally undesirable (e.g., Haufler and Schjelderup, 2004).

An issue that has not been explicitly analyzed in this paper is how harmonization affects international cartels when one firm is located outside the harmonizing area. The answer to this question, however, follows from our analysis. Harmonization to a minimum standard, say, on average raises the tax wedge and thus the effective cost of the low tax firm in the harmonizing area, thereby reducing its incentive to defect and export into the outside firm's market. For the firm located outside the Union, the effect of harmonization depends on its cost (dis-)advantage. If it has lower costs than any firm located in the Union, harmonization makes it more attractive to export to the harmonizing area since effective costs there have gone up. Thus profit in the deviating as well as in the punishment phase of the game has risen. If the outside 
firm has higher costs, harmonization in the Union strengthens the incentive of the outside firm to remain in the cartel. Taken together, harmonization has a dual effect: on the one hand it stabilizes and segments cartels within the harmonizing union, but it may, on the other hand, decrease or increase the incentive to defect in a market with firms located outside the harmonizing union. In the latter case, however, for the area that harmonizes, losing market shares to a foreign firm must be traded off against the benefits to consumers from lower prices.

\section{Appendix}

As it is always the low-cost firm which is more likely to leave the cartel, we have to differentiate its critical discount factor,

$$
\bar{\theta}_{i}^{m}=\frac{\alpha_{i}^{2}}{\alpha_{i}^{2}-8 \alpha_{j}\left(\tilde{c}_{j}-\tilde{c}_{i}\right)},
$$

for the changes in tax rates resp. deductibility factors in order to get the effects of harmonization on cartel stability. This gives

$$
d \bar{\theta}_{i}^{m}=\frac{\partial \bar{\theta}_{i}^{m}}{\partial \tilde{c}_{i}} \cdot \frac{\partial \tilde{c}_{i}}{\partial \epsilon_{i}} \cdot \frac{\partial \epsilon_{i}}{\partial t_{i}} \cdot d t_{i}+\frac{\partial \bar{\theta}_{i}^{m}}{\partial \tilde{c}_{j}} \cdot \frac{\partial \tilde{c}_{j}}{\partial \epsilon_{j}} \cdot \frac{\partial \epsilon_{j}}{\partial t_{j}} \cdot d t_{j}
$$

and

$$
d \bar{\theta}_{i}^{m}=\frac{\partial \bar{\theta}_{i}^{m}}{\partial \tilde{c}_{i}} \cdot \frac{\partial \tilde{c}_{i}}{\partial \epsilon_{i}} \cdot \frac{\partial \epsilon_{i}}{\partial \gamma_{i}} \cdot d \gamma_{i}+\frac{\partial \bar{\theta}_{i}^{m}}{\partial \tilde{c}_{j}} \cdot \frac{\partial \tilde{c}_{j}}{\partial \epsilon_{j}} \cdot \frac{\partial \epsilon_{j}}{\partial \gamma_{j}} \cdot d \gamma_{j}
$$

Therefore, we need

$$
\begin{aligned}
\frac{\partial \bar{\theta}_{i}^{m}}{\partial \tilde{c}_{i}} & =-\frac{2 \alpha_{i}\left[\alpha_{i}^{2}-8 \alpha_{j}\left(\tilde{c}_{j}-\tilde{c}_{i}\right)\right]+\alpha_{i}^{2}\left(6 \alpha_{i}-8\left(\tilde{c}_{j}-\tilde{c}_{i}\right)\right)}{\left[\alpha_{i}^{2}-8 \alpha_{j}\left(\tilde{c}_{j}-\tilde{c}_{i}\right)\right]^{2}}<0 \\
\frac{\partial \tilde{c}_{i}}{\partial \epsilon_{i}} & =c=\frac{\partial \tilde{c}_{j}}{\partial \epsilon_{j}}>0 \\
\frac{\partial \bar{\theta}_{i}^{m}}{\partial \tilde{c}_{j}} & =\frac{8 \alpha_{i}^{2}\left[\alpha_{j}-\left(\tilde{c}_{j}-\tilde{c}_{i}\right)\right]}{\left[\alpha_{i}^{2}-8 \alpha_{j}\left(\tilde{c}_{j}-\tilde{c}_{i}\right)\right]^{2}}=\frac{8 \alpha_{i}^{2}\left[\alpha_{i}-2\left(\tilde{c}_{j}-\tilde{c}_{i}\right)\right]}{\left[\alpha_{i}^{2}-8 \alpha_{j}\left(\tilde{c}_{j}-\tilde{c}_{i}\right)\right]^{2}}>0,
\end{aligned}
$$

where the inequality in (27) and (29) holds because $\alpha_{i}-2\left(\tilde{c}_{j}-\tilde{c}_{i}\right)>0$ from $\pi^{E}>0$ in equation (5). 
Moreover, we have $\epsilon_{i}=\frac{1-\gamma_{i} t_{i}}{1-t_{i}}$ and thus

$$
\frac{\partial \epsilon_{i}}{\partial \gamma_{i}}=-\frac{t_{i}}{1-t_{i}}<0
$$

and

$$
\frac{\partial \epsilon_{i}}{\partial t_{i}}=\frac{1-\gamma_{i}}{\left(1-t_{i}\right)^{2}} \begin{cases}>0 & \text { if } \gamma_{i}<1 \\ <0 & \text { if } \gamma_{i}>1\end{cases}
$$

\section{References}

Abreu, D., 1986. Extremal Equilibria of Oligopoly Supergames, Journal of Economic Theory 39, 191-225.

Brennan, G., and J. Buchanan, 1980. The Power to Tax: Analytical Foundations of a Fiscal Constitution, Cambridge University Press.

Commission of the European Communities, 2001. Towards an Internal Market Without Tax Obstacles, COM (2001), 582 final, 23.

Edwards, J., and M. Keen, 1996. Tax Competition and Leviathan, European Economic Review 40, 113-134.

European Commission, 1996. A Common System of Value Added Taxation. A Programme for the Internal Market, Document COM (96) 328. Brussels.

Froot, K., and P.D. Klemperer, 1989. Exchange Rate Pass-Through when Market Share Matters, American Economic Review 79, 637-654.

Fudenberg, D., and E. Maskin, 1986. The Folk Theorem in Repeated Games with Discounting or with Incomplete Information, Econometrica 54, 533-554.

Gendron, P-P., 2001. Corporation Tax Asymmetries and Cartel Unity, International Tax and Public Finance 8, 659-674.

Haufler, A., and G. Schjelderup, 2004. Tacit Collusion and International Commodity Taxation, Journal of Public Economics 88, 577-600.

Kanbur, R., and M. Keen, 1993. Jeux sans Frontières: Tax Competition and Tax Coordination when Countries Differ in Size, American Economic Review 83, 877-892. 
Keen, M., 1987. Welfare Effects of Commodity Tax Harmonization, Journal of Public Economics 33, 107-114.

Keen, M., 1989. Pareto-Improving Indirect Tax Harmonization, European Economic Review 33, 1-12.

Keen, M., Lahiri, S., and P. Raimondos-Møller, 1998. When Is Policy Harmonization Desirable? EPRU working paper 1998/2, Copenhagen Business School.

King, S.P., 1997. National Competition Policy, Economic Record 73, 270-284.

Lommerud, K.E., and L. Sørgard, 2001. Trade Liberalization and Cartel Stability, Review of International Economics 9, 343-355.

McLure, C.E, 1986. "Tax Competition: Is What's Good for the Private Goose also Good for the Public Gander? National Tax Journal XXXIX, 341-346.

Martin, S., 1993. Advanced Industrial Organization, Blackwell, Mass.

Marvel, H., 1982. Exclusive Dealing, Journal of Law and Economics 25, 1-26.

Meckl, J., 1996. Market Power of Firms and Exchange Rate Fluctuations, Journal of Economics 63, 57-77.

Mintz, J., 2004. Corporate Tax Harmonization in Europe: It's All About Compliance, International Tax and Public Finance 11, 221-234.

Mintz, J., and H. Tulkens, 1986. Commodity Tax Competition Between Member States of a Federation: Equilibrium and Efficiency, Journal of Public Economics 29, 133-172.

Monti, M., 2001. Why We Should Be Concerned with Cartels and Collusive Behavior, in: Fighting Cartels - Why and How? Swedish Competition Authority Individual Chapters (ISBN 91-88566-26-9).

OECD, 2000. Report on Hard Core Cartels.

Pinto, B., 1986. Repeated Games and the Reciprocal Dumping Model of Trade, Journal of International Economics 20, 357-366.

Rauscher, M., 1998. Leviathan and Competition Among Jurisdictions: The Case of Benefit Taxation, Journal of Urban Economics 44, 59-67. 
Rotemberg, J., and G. Saloner, 1989. Tariffs vs. Quotas with Implicit Collusion, Canadian Journal of Economics 22, 237-244.

Scherer, F., 1996. International Trade and Competition Policy, Discussion paper No. 96-18, Industrial Economics and International Management Series, Harvard University.

Sinn, H.W., 1987. Capital Income Taxation and Resource Allocation, NorthHolland.

Slade, M., 1995. Empirical Games: The Oligopoly Case, Canadian Journal of Economics 96, 368-402.

Steen, F., and L. Sørgard, 1999. Semicollusion in the Norwegian Cement Market, European Economic Review 43, 1775-1796.

Tirole, J., 1988. The Theory of Industrial Organisation, MIT Press, Cambridge, Mass. 